\title{
ROLE OF MEDICAL EXPULSIVE THERAPY IN URETEROLITHIASIS
}

\author{
SUDIP DAS GUPTA ${ }^{1}$, MOHAMMED MIZANUR RAHMAN ${ }^{1}$, MD. ZAHURUL HAQUE ${ }^{1}$, MD.NAZRUL ISLAM \\ MRIDHA $^{1}$, MRINMOY BISWAS ${ }^{1}$, MD. ABU NASER WAHID ${ }^{1}$
}

Department of Urology, Sir Salimullah Medical College, Dhaka.

\begin{abstract}
:
Objective: Medical expulsive therapy (MET) for urolithiasis has gained increasing attention in the last few years. MET is an excellent treatment modality for ureteric stones in the appropriately selected patients. This study was carried out to study the role of MET in the treatment of upper/middle/lower ureteric and VUJ calculi to compare the safety and efficacy of tamsulosin and tamsulosin with Deflazacort as medical expulsive therapy for ureteric stones.

Materials and methods: Between July 2013 to June 2014, 105 adult patients with ureteric stones sized $5 \mathrm{~mm}$ to $10 \mathrm{~mm}$ were randomized equally to treatment with tamsulosin or tamsulosin with deflazacort. Therapy was given for a maximum of 6 weeks. The stone expulsion rate, mean time to expulsion (days), site of stones passed, endoscopic treatment (URS) and adverse effects of the drugs were noted. Statistical analysis was done by using student's t-test and chi-square test.

Results: Total 105 patients were included in this study. Only Tamsulosin $0.4 m g$ once daily was given to 53 patients in group A. Fifty two patients in group $B$ were treated with Tamsulosin $0.4 \mathrm{mg}$ once daily plus Deflazacort $6 \mathrm{mg}$ twice daily. The stone expulsion rate was $84.9 \%$ (45/53) in group $A$ and $96.1 \%$ (50/52) in group B. Mean expulsion time (days) was shorter in group $B$. It was 4.96 days in group $B$ compared with group $A$ ( 8.53 days) which was highly statistically significant.

Conclusion: Medical expulsive therapy (MET) for ureteric stones using tamsulosin and tamsulosin with Deflazacort is safe and efficacious. Tamsulosin with Deflazacort is very effective in expelling stones present in all the levels of the ureter.
\end{abstract}

Key words: Tamsulosin, Deflazacort, Urinary calculi.

Bangladesh J. Urol. 2014; 17(2): 67-70

\section{Introduction:}

The incidence of urinary stones has been increasing day by day. Ureteral stones contribute to $22 \%$ of all urinary tract stones[1].Ureteral stones of any size may be associated with obstructive uropathy. Care must be taken to prevent damage to the kidney whether choosing expectant or active management. In last 20 years, the introduction of new, minimally invasive procedures like percutaneous nephrolithotomy ( $P C N L)$, flexible ureteroscopy, extracorporeal shock wave lithotripsy (ESWL), ureterorenoscopy (URS) and laser for ureteral stones have considerably changed the historical therapy

Correspondence: Sudip Das Gupta, Department of Urology, Sir Salimullah Medical College, Dhaka, Email: sudipuro@gmail.com for this disease with a substantial increment in treatment costs[2]. But still medical expulsive therapy plays an important role in the management of ureteric stones in selected cases. Medical expulsive therapy (MET) may be defined as adjuvancy to the passage of stone into the bladder with medical therapy.Medical expulsive therapy developed after an understanding of the various physiologic and pathophysiologic basis for urinary stones. The ureter is lined by smooth muscle cells with alpha-1 adrenergic receptors[3,4]. Because of this distribution of alpha ${ }_{1}$-adrenergic receptors in the lower

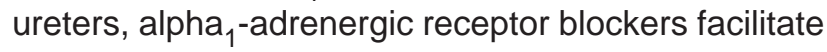
stone clearance by reducing smooth muscle tonus and increasing urine bolus[5]. Receptor blockade inhibits 
both basal smooth muscle tone and hyperperistaltic uncoordinated frequency in order to maintain tonic propulsive contractions All these lead to an increase in the intramural pressure gradient above the stone, as well as a decrease in the intramural pressure gradient below the stone, thus increase the stone expulsion rate[6]. So a selective alpha ${ }_{1}$-adrenergic receptor blocker tamsulosin has been used to increase the stone free rate and decrease the morbidity of watchful waiting approach. Tamsulosin has a proven role in increasing the stone expulsion rate and in decreasing expulsion time.

Finally it has been shown that ureteric calculi induce inflammatory changes and submucosal edema in proximity to a stone that may worsen ureteric obstruction, thus increasing the risk of impaction and retention ${ }^{5}$. Thus glucocorticoid can facilitate stone expulsion by reducing edema. Deflazacort facilitates stone expulsion by this mechanism[2]. This study was carried out in the Department of Urology, Sir Salimullah Medical College Mitford Hospital, Dhaka on 105 patients who came with ureteric stones and were treated with medical expulsive therapy (MET) using tamsulosin and deflazacort.

\section{Material and methods:}

The present study was undertaken in the Department of Urology Sir Salimullah Medical College Mitford Hospital, Dhaka. It was carried out over a period of 12 months from July 2013 to June 2014. Symptomatic patients with solitary ureteric stone irrespective of their levels in the ureter demonstrated on plain x-ray KUB were included in the study. Patients with active urinary tract infections, fever, acute renal failure, chronic renal failure, history of urinary surgery, uncorrected distal obstruction and marked hydronephrosis were excluded from the study.

Total 105 patients were included in the study. They were randomized into two groups. Fifty three patients were included in group A which were treated with tamsulosin $0.4 \mathrm{mg}$ once daily and 52 patients were included in group $B$ which were treated with tamsulosin $0.4 \mathrm{mg}$ once daily plus Deflazacort 6mg B.D. Treatment was given for a maximum of 6(six) weeks or until stone expulsion (whichever earlier). Patients were followed with USG of KUB and plain X-ray KUB after 2 days of symptoms relief, weekly thereafter till stone passed/for 6weeks (whichever early).

The maximum follow-up was for 6 (six) weeks after which patients underwent URS for removal of stones that were not expelled. The stone expulsion rate, stone expulsion time, number of pain episodes, analgesics used, endoscopic treatment (URS) and adverse effects of drugs were noted. Expulsion of the stone was confirmed by Plain X-ray KUB. Statistical analysis was done by using student's t-test and chi-square test.

A $p$-value $<0.05$ was considered statistically significant.

\section{Results:}

Total 105 patients were included in this study. Only Tamsulosin $0.4 \mathrm{mg}$ once daily was given to 53 patients in group A. Fiftytwo patients in group B were treated with Tamsulosin $0.4 \mathrm{mg}$ once daily plus Deflazacort $6 \mathrm{mg}$ twice daily. No statistical significant differences were observed regarding patient's age, sex and stone size.

Fifty three patients were included in group A (only Tamsulosin $0.4 \mathrm{mg}$ once daily) and 52 patients were in group B (Tamsulosin plus Deflazacort). There was a higher expulsion rate in both treatment groups

The stone expulsion rate was $84.9 \%(45 / 53)$ in group $A$ and $96.1 \%(50 / 52)$ in group B. Mean expulsion time (days) was shorter in group $B$. It was 4.96 days in group B compared with group A (8.53 days) which was highly statistically significant (Table1). Eight patients required stone removal by URS in group $A$ and two patients in group B. Sites of stones passed in group $A$ and group $B$ were respectively as follows- upper $5 / 7,7 / 8$ middle $5 / 8$, 8/9 lower 7/9, 10/10 VUJ 28/29, 25/25 (Table-II).

Table-I

Stone expulsion rate and time:

\begin{tabular}{lccc}
\hline & GroupA & Group B & P-Value \\
\hline Expulsion rate & $84.9 \%(45 / 53)$ & $96.1 \%(50 / 52)$ & 0.692 \\
Mean expulsion & 8.53 & 4.96 & 0.031 \\
time (days) & & & \\
\hline
\end{tabular}

Table-II

Site of stone

\begin{tabular}{lcc}
\hline Site & $\begin{array}{c}\text { GroupA } \\
\text { (Passed/Total) }\end{array}$ & $\begin{array}{c}\text { Group B } \\
\text { (Passed/Total) }\end{array}$ \\
\hline Upper & $5 / 7$ & $7 / 8$ \\
Middle & $5 / 8$ & $8 / 9$ \\
Lower & $7 / 9$ & $10 / 10$ \\
VuJ & $28 / 29$ & $25 / 25$ \\
\hline Total & $45 / 53$ & $50 / 52$ \\
\hline
\end{tabular}

\section{Discussion:}

Ureteric stones are the commonly encountered problems in daily practice. Sixty eight percent of the ureteric stones are located in the lower third of ureter. Factors influencing 
stone expulsion are site of the stone, size of the stone, structure, and inflammation, presence of ureteral spasm and anatomy of ureter[8]. Medical expulsive therapy acts by relaxation of smooth muscle and by reducing edema and spasm. MET has been recognized as an established treatment option for ureteric stone by facilitating stone expulsion. Now the question may arise who can be treated with medical expulsive therapy. In patients with ureteral stones less than $10 \mathrm{~mm}$, no clinical evidence of sepsis and adequate renal functional reserve, appropriate medical therapy with periodic evaluation is recommended as initial treatment. But patients with unremitting or recurrent disabling pain, persistent urinary obstruction, infection, solitary kidney, renal insufficiency need intervention.

According to the earlier studies, the expulsion rate of distal ureteric stones by watchful waiting is $25 \%-53 \%$ in distal ureter and $10 \%-53 \%$ in proximal ureter with a mean expulsion time greater than 10 days and is associated with a high analgesic requirement even for stones $<4 \mathrm{~mm}$. In order to improve the expulsion rate and reduce the analgesic requirement, conservative therapy is considered for ureteric stones. Most common adrenoreceptors found in the ureter are alpha ${ }_{1 \mathrm{D}}$ and alpha1A. Therefore, studies have been carried out to determine the effect of a combined alpha ${ }_{1 \mathrm{~A}}$ and alpha $\mathrm{AD}_{1 \mathrm{D}}$ selective agonist, tamsulosin which showed an improved expulsion rate of medium sized (3-10mm) stones. In this study an expulsion rate of $84.9 \%$ with tamsulosin was observed which is better than studies by K.Jayant et al (65.5\%). Thus tamsulosin represents a noninvasive and cost-effective alternative to interventional approach. Although medical expulsive therapy has become a standard treatment option, it is still underused.

We used Deflazacort, glucocorticoid based on reports by Propiglia $\mathrm{F}$ et al who showed the role of corticosteroid as medical expulsive therapy for ureteric stones.

Deflazacort is an oxazoline derivative of prednisolone with an anti-inflammatory activity. Deflazacort is associated with less serious metabolic sequelae than prednisolone. Deflazacort is used to aid stone passage. The rationale for this treatment is that it reduces stone induced oedema and hence allows a calculus to pass. Steroids combined with an alpha blocker proved more efficacious than either a steroid or alpha blocker alone. In this study in the group treated with Tamsulosin and Deflazacort, the stone expulsion rate was $96.1 \%$ which is higher than the group treated with tamsulosin (84.9\%) alone. This is similar with the study done by Propiglia et al. Mean expulsion time (days) was shorter in the group treated with both tamsulosin plus deflazacort which was 4.96 days compared to 8.53 days in group A (treated with Tamsulosin).

\section{Conclusion:}

The results of the present study show that the addition of deflazacort with tamsulosin increases ureteric stone expulsion quite significantly along with significant control of pain, significantly less analgesic requirement. Combination of alpha-blockers and corticosteroid are more effective to single therapy no recommendation can be made for stone more than $10 \mathrm{~mm}$. Medical expulsive therapy is a now an established modality of treatment. It reduces the need for hospitalization and limits the need for surgical intervention to remove the stones.

Conflict of Interest: None declared

\section{References}

1. Hollings worth JM, Roger MAM, Kaufman SR et al, Medical therapy to facilitate urinary stone passage: a meta-analysis. Lancet. 2006; 368:1171-9.

2. Ranjan R, Kumari P, Mundu M, Baxla R. The role of tamsulosin and deflazacort in the expulsion of up to 6 mid and lower ureteric calculi. International journal of Urology 2014; 11:1-5.

3. Porpiglia $F$, Vaccino $D$, Billia $M$ et al. Corticosteroids and tamsulosin in the medical expulsive therapy for symptomatic distal ureteral stones: single drugor association? Eur. Urol. 2006; 50: 339-44.

4. Zhong $\mathrm{H}$ and Minneman KP. á ${ }_{1}$-Adrenoceptor subtypes. Eur J Pharmacol 1999; 375: 261-276.

5. Kupeli B, Irkilatl L, Gurocak S, Tune L, Kirac M, Karaoglan $U$ et al. Does Tamsulosin enhance lower ureteral stone clearance with or without shockwave lithotripsy. Urology 2004; 64: 1111-1115.

6. Dellabella M, Milanese G, Muzzonigro G. Efficacy of Tamsulosin in the medical management of juxtavesical ureteral stones. Journal of Urology 2003; 170: 2202-2205.

7. Jayant K, Agrawal R, Agrawal S. Tamsulosin verses tamsulosin plus tadalafil as medical expulsive therapy for lower ureteric stones: A randomize control trial. International journal of Urology 2014; 21:1012-1015.

8. Cervenakov I, Fillo J, Mardiak J et al. Speedy elimination of ureterolithiasis in lower part of ureters 
with the alpha ${ }_{1}$-blocker tamsulosin. Int Urol Nephrol 2002; 34: 25-29.

9. Segura JW, Premingcr GM, Assimos DG, et al. Ureteral stones: Clinical Guidelines Panel summary report on the management of ureteral calculi. J Urol 1997; 158: 1915-1921.

10. Wolf JS Jr. Treatment selection and outcomes: ureteral calculi. Urol. Clin.North Am. 2007; 34: 421-30.

11. Dellabella M, Milanese G, Muzzonigro G. Efficacy of Tamsulosin in the medical management of juxtavesical ureteral stones. Journal of Urology 2003; 170: 2202-2205.

12. Autorino R, Sio MD, Damiano R, Lorenzo GD, Perdona S, Russo A et al. The use of Tamsulosin in the medical treatment of ureteral calculi : where we do stand? Urological research 2005; 33:460-464.

13. Cooper JT, Stack GM, Cooper TP. Intensive medical management of ureteral calculi. Urology 2000; 56: 575-578.
14. Labrecque J, Randolph R, Davis R. Benign prostatic hyperplasia: an overview for pharmacists. The American Journal of Managed Carel999;5:661-668.

15. Whitfield $\mathrm{HN}$. The management of ureteric stones. Part II: therapy. BJU International 1999; 54: 916-921.

16. Yanardag H, Goktas S, Kibar Y Kilic S Erduran D. Intermittent Tamsulosin therapy in men with lower urinary tract symptoms. J Urol 2005; 173: 155-157.

17. Yilmaz E, Batislam E, Basar MM, Tuglu D, Ferhat $\mathrm{M}$, Basar $\mathrm{H}$. The comparison and efficacy of 3 different áadrenergic blockers for distal ureteral stones. J Urol 2005; 173: 2010-2012.

Abbreviations:

MET : Medical expulsive therapy

VUJ : Vesicoureteric Junction

URS : Uretero Renoscopy 